A - Research concept and design

B - Collection and/or assembly of data

$\mathrm{C}$ - Data analysis and interpretation

D - Writing the article

E - Critical revision of the article

F - Final approval of article

\section{Monitoring body mass status during the COVID-19 quarantine in combat and aesthetic sports}

\author{
Junaidi Junaidi*1,A-C (D), Tirto Apriyanto Tirto ${ }^{1, C, E}$ (D), \\ Bagus Winata Bagus ${ }^{2, D-F}$ iD, Laily Inarota ${ }^{3, E-F}$ iD \\ ${ }^{1}$ Universitas Negeri Jakarta, Indonesia \\ ${ }^{2}$ Institut Teknologi Bandung, Indonesia \\ ${ }^{3}$ Vrije Universiteit Medical Center, Netherlands
}

*Correspondence: Junaidi Junaidi, Universitas Negeri Jakarta, Indonesia; email: junaidi.sportmed@unj.ac.id

\title{
Abstract
}

Introduction: Body mass is a crucial matter in the midst of the COVID-19 pandemic, especially in combat and aesthetic sports which use body mass or weight as a variable in determining class/division for a match. This study aims to analyze and compare the effects of COVID-19 quarantining on body mass between combat and aesthetic sports athletes.

Material and methods: 150 male athletes, in the age group of 20-23 years old, participated in this study. They were grouped into two. The first consisted of 100 combat sports athletes, including boxing $(\mathrm{n}=25)$, Judo $(\mathrm{n}=20)$, Karate $(n=20)$, Taekwondo $(n=20)$, and Pencak Silat $(n=15)$. The second group was comprised of 50 aesthetic sports athletes, including aerobic $(n=20)$, artistic gymnastics $(n=15)$, and diving $(n=15)$. This study focused on two parts: body mass measurement before the large-scale social restrictions in DKI Jakarta was implemented (Pre-LSCR) and body mass measurement during the large-scale social restrictions in DKI Jakarta (During-LSCR). A Life Satisfaction (LS) questionnaire was administered to all participants During-LSCR.

Results: The LS questionnaire showed a higher level of the "very satisfying" response in aesthetic sports athletes regarding doing sports During-LSCR (90\%), compared to that in combat sports athletes (16\%). On the other hand, there were significant differences in body mass $(p=0.001)$ and body fat percentage $(p=0.001)$ between combat sports and aesthetic sports athletes.

Conclusions: This study shows that aesthetic sports lighter than combat sports during the 20-day quarantine period in the COVID-19 pandemic.

Keywords: contact sports, health, martial arts, non-contact sport, pandemic

\section{Introduction}

Since the World Health Organization stated that the novel coronavirus infection (COVID-19) was a global pandemic on March 11, 2020, various countries have experienced many changes and losses due to the massive spread of the virus [1-3]. The sports world has also experienced the effects of the pandemic, including the cancellation or postponement of international competitions or holding matches without spectators $[4,5]$. Pertaining to the topic of health and sports during the pandemic, studies show that people have experienced a change in their circadian cycle and their $\operatorname{diet}[6,7]$. 
In fact, it was found that people have been doing fewer physical activities during the pandemic [6]. In general, studies show that policies imposed by the government on the people that require the latter to stay at home or self-quarantine are the main reason for the problems above [7,8]. Moreover, some studies have measured the effects of the pandemic on the increase in body mass [9], in stress level [10], and in the risks of diseases such as atherosclerotic and cardiovascular diseases due to a lack of physical activities [11].

Combat sport is a category of contact sport that uses body mass or weight as a variable in determining class/ division for matches [12]. Therefore, it is no wonder that many combat sports athletes try many things to reduce their body mass into a certain body ideal so that they can fight in lighter divisions [12,13]. It will be advantageous since they will get smaller and weaker opponents [14]. Previous studies show that combat sports athletes can generally reduce their body mass by as much as $2 \%$ to $10 \%$ of their body ideal in a period of one week before a match [15]. However, experts concluded that it might disrupt their metabolism, increase the risk of dehydration, and even cause death in extreme cases $[15,16]$.

Besides combat sports, aesthetic sports such as rhythmic and artistic gymnastics also use body mass as a variable in determining the quality of their performance $[12,17]$. In general, athletes or their coaches expect higher scores when their body mass and shape conform to a perceived body ideal $[18,19]$. However, aesthetic sports are different from combat sports in that the former are non-contact sports while the latter are contact sports. Due to their different characteristics, both combat and aesthetic sports have different types of exercises and training. Moreover, even though athletes in all sports have been experiencing difficulties in practicing during the pandemic, contact sports athletes have found it particularly difficult since they have to adhere to the physical distancing policy. Unlike their combat sports counterparts, aesthetic sports athletes are still able to train well since aesthetic sports are noncontact in nature.

The limitation of quarantine and social distancing policies has also caused athletes to change their diet and volume of training, which leads to a change in their body mass [20]. This especially happens to combat sports athletes who cannot do real training due to physical distancing policies. We interested to study that conducted by Herrera-Valenzuela et al [21]. The study evaluated the effect of COVID-19 quarantine on body mass in 234 men's combat sports athletes, and concluded that combat sports athletes experienced an increase in body mass during the COVID-19 quarantine. According to this study, and without any intention to diminish the value of benefits of the study conducted by Herrera-Valenzuela et al., we noted that there was also no attention to measures another type sports such as aesthetic sports.

Therefore, it will be interesting to uncover the extent of athletes' body mass changes in both combat sports and aesthetic sports during the pandemic. Furthermore, this study aims to analyze and compare the effects of COVID-19 quarantine on body mass between combat and aesthetic sports athletes. We hypothesized that combat sports athletes experienced higher increase in their body mass than aesthetic sports athletes due to the characteristics of combat sports as contact sports. It is because during the pandemic, contact sports athletes cannot train well because they have to adhere to physical distancing rules.

\section{Material and methods}

This cross-sectional, prospective, multi-center study involved and evaluated a sample of 150 male athlete participants, in the age group of 20-23 years old. They were grouped into two categories according to the type of sports they have mostly performed. Group I consisted of 100 combat sports athletes, including boxing $(\mathrm{n}=25)$, Judo $(\mathrm{n}=20)$, Karate $(\mathrm{n}=20)$, Taekwondo $(\mathrm{n}=20)$, and Pencak Silat $(\mathrm{n}=15)$. Group II consisted of 50 aesthetic sports athletes, including aerobic $(\mathrm{n}=20)$, artistic gymnastics $(\mathrm{n}=15)$, synchronized diving $(n=15)$. All participants in this study were athletes from DKI Jakarta regional athlete training agency (PELATDA DKI Jakarta). All participants were informed about the benefits and risks of the study through Google Form documents before they signed an informed consent signifying that they were willing to participate in this study. This study passed the ethics committee test issued by The Ethics Committee of Universitas Negeri Jakarta (380/UN40.15/PR.06/2020) and followed the provisions of the Declaration of Helsinki. Participants' characteristics are given in Table 1.

\section{Overview of measurements}

In 2020, DKI Jakarta, the capital of Indonesia implemented a large-scale social restrictions (LSCR) policy from 14 April to 21 December. During this period, all activities in the region were heavily restricted, including sporting activities. All regional athletes in DKI Jakarta were mandated to train and exercise independently at home, and sent the report training to coach by online. In consideration of this restriction, the results of this study were categorized into two parts: body mass measurement before the large-scale social restrictions in DKI Jakarta (Pre-LSCR) and body mass measurement 
Tab. 1. Participants' characteristics

\begin{tabular}{lccc}
\hline Group I & Age (years) & Height $(\mathrm{cm})$ & Experience $($ years $)$ \\
\hline Boxing $(\bar{X} \pm \mathrm{SD})$ & $21.88 \pm 1.13$ & $165.84 \pm 8.71$ & $7.08 \pm 0.64$ \\
Judo $(\bar{X} \pm \mathrm{SD})$ & $21.10 \pm 1.55$ & $162.95 \pm 7.11$ & $6.70 \pm 0.73$ \\
KRT $(\bar{X} \pm \mathrm{SD})$ & $21.60 \pm 1.35$ & $162.65 \pm 9.62$ & $6.85 \pm 0.93$ \\
TKW $(\bar{X} \pm \mathrm{SD})$ & $21.55 \pm 1.57$ & $167.40 \pm 7.83$ & $6.90 \pm 0.79$ \\
PKS $(\bar{X} \pm \mathrm{SD})$ & $21.33 \pm 0.90$ & $167.07 \pm 10.56$ & $6.73 \pm 0.80$ \\
Average & $21.52 \pm 1.34$ & $165.12 \pm 8.79$ & $6.87 \pm 0.77$ \\
\hline Group II & Age $($ years $)$ & Height $(\mathrm{cm})$ & Experience $($ years $)$ \\
\hline Aerobic $(\bar{X} \pm \mathrm{SD})$ & $21.25 \pm 1.12$ & $161.65 \pm 7.39$ & $6.80 \pm 0.83$ \\
AGY $(\bar{X} \pm \mathrm{SD})$ & $21.13 \pm 1.06$ & $161.20 \pm 8.05$ & $6.73 \pm 0.70$ \\
Synchronized diving $(\bar{X} \pm \mathrm{SD})$ & $21.93 \pm 1.03$ & $156.07 \pm 5.85$ & $6.73 \pm 0.80$ \\
Average & $21.42 \pm 1.11$ & $159.84 \pm 7.46$ & $6.76 \pm 0.77$ \\
\hline
\end{tabular}

KRT - Karate; TKW - Taekwondo; PKS - Pencak Silat; AGY - Artistic gymnastics. Group I - combat sports; Group II - aesthetic sports.

during the large-scale social restrictions in DKI Jakarta (During-LSCR). Pre-LSCR was conducted on 10-12 April 2020 and During-LSCR was conducted on 28 December 2020.

Pre-LSCR measurement was conducted directly at the sports hall of KONI DKI Jakarta. It was a collection of preliminary data in preparation for all athletes to self-quarantine. Body mass and percentage body fat was measured using Tanita Digital BC-541 Body Composition. Meanwhile, During-LSCR measurement was conducted online, in which all athletes were required to fill in a questionnaire. The questionnaire was comprised of items asking respondent's name, sex, sport category, Life Satisfaction (LS) questionnaire, and current body mass and percentage body fat. It was administered through a Google Forms link sent via WhatsApp or email to the respondents. In the questionnaire, we encouraged all participants to use a well calibrated scale and to do the measurement between 07.00-08.00 a.m. to avoid data bias.

\section{Pre-LSCR measurement}

Pre-LSCR measurement was conducted in three days, during which a maximum of 50 participants were measured per day. 10 Tanita Digital BC-541 Body Composition instruments were prepared in the front yard of the Sport Hall of KONI DKI Jakarta. Each weight scale was handled by one administrator, who was responsible for measuring the athletes, verifying the results, and recording the measurement results. The measurement was conducted in the morning, between 07.00 and
08.00 a.m., with warm weather $\left(23-24^{\circ} \mathrm{C}\right)$ and relative humidity (65-70\%). All measurement steps and procedures were done by strictly following the existing health protocol. All participants wore minimal clothes and were barefooted.

\section{Life Satisfaction questionnaire (LS)}

LS was adopted from and based on a previous questionnaire's method [22]. The questionnaire consisted of two major questions. The first asked athletes' response regarding their satisfaction toward trainings or exercises during LSCR. The second asked for comparison of athletes' satisfaction between practicing Pre-LSCR and practicing during LSCR. Specifically, the first question was: Are you satisfied with performing independent training and exercise DuringLSCR? The participants would respond by choosing the option "very unsatisfying" or "very satisfying". Meanwhile, the second question was: Is training During-LSCR better than training Pre-LSCR? The participants would respond by choosing "much worse" or "much better".

\section{Statistical analysis}

All data was exported using 2016 Microsoft Office Excel ${ }^{\circledR}$ electronic spreadsheet and was further analyzed using SPSS $®$ version 26.0. Normal data distribution was tested using the Shapiro-Wilk test. A two-factor repeated measures analysis of variance (ANOVA) was calculated to find the difference between Pre-LSCR and During-LSCR on each sport type and overall, between 
Group I and Group II. The 95\% confidence interval and percentage of changes were calculated. Statistical significance was accepted at $\mathrm{p}<0.05$.

\section{Results}

Table 2 and Table 3 shows mean and SD values, as well as percentage of changes and differences among all sport types in Pre-LSCR and During-LSCR.

\section{Body mass}

A two-factor ANOVA showed a significant main effect for group ( $p=0.001)$. Specifically, aerobic athletes were lighter than boxing athletes $(p=0.003)$, judo athletes $(p=0.027)$, karate athletes $(p=0.023)$, taekwondo athletes $(p=0.025)$, pencak silat athletes $(p=0.005)$, and synchronized diving athletes $(p=0.024)$. Artistic gymnastics were lighter than boxing athletes $(p=0.001)$, judo athletes $(p=0.013)$, karate athletes $(p=0.011)$, taekwondo athletes $(p=0.012)$, pencak silat

Tab. 2. Body mass changes between combat sports athletes and aesthetic sports athletes during the COVID-19 quarantine (the values are presented as mean $\pm \mathrm{SD}$ )

\begin{tabular}{|c|c|c|c|}
\hline Group I (combat sports) & $\begin{array}{c}\text { Body mass } \\
\text { Pre-LSCR (kg) }\end{array}$ & $\begin{array}{c}\text { Body mass } \\
\text { During-LSCR (kg) }\end{array}$ & $\begin{array}{l}\text { Difference in body } \\
\text { mass }(\mathrm{kg})\end{array}$ \\
\hline Boxing & $60.38 \pm 14.43$ & $61.14 \pm 14.70$ & $0.76 \pm 2.23$ \\
\hline Judo & $61.40 \pm 8.63$ & $62.56 \pm 9.42$ & $1.17 \pm 1.20$ \\
\hline Karate & $61.45 \pm 11.68$ & $62.80 \pm 12.22$ & $1.36 \pm 1.72$ \\
\hline Taekwondo & $61.58 \pm 8.49$ & $62.54 \pm 9.47$ & $0.96 \pm 1.70$ \\
\hline Pencak Silat & $63.79 \pm 13.65$ & $64.10 \pm 14.17$ & $0.31 \pm 1.81$ \\
\hline \multicolumn{4}{|l|}{ Group II (aesthetic sports) } \\
\hline Aerobic & $56.17 \pm 11.59$ & $56.92 \pm 11.51^{\dagger \star^{\wedge * \#+}}$ & $0.75 \pm 1.55$ \\
\hline Artistic gymnastics & $52.33 \pm 13.10$ & $52.95 \pm 13.15^{\dagger \uparrow * \#}$ & $0.66 \pm 2.01$ \\
\hline Synchronized diving & $50.43 \pm 3.24$ & $50.72 \pm 4.92^{\dagger * * \#}$ & $0.29 \pm 3.30$ \\
\hline
\end{tabular}

Pre-LSCR - Pre-large-scale social restrictions in DKI Jakarta; During-LSCR - during the large-scale social restrictions in DKI Jakarta. $\dagger$ values significantly different compared with Boxing, $\ddagger$ values significantly different compared with Judo, ^ values significantly different compared with karate, * values significantly different compared with Taekwondo, \# values significantly different compared with Pencak Silat, + values significantly different compared with Diving.

Tab. 3. Body fat percentage changes between combat sports athletes and aesthetic sports athletes during the COVID-19 quarantine (the values are presented as mean $\pm \mathrm{SD}$ )

\begin{tabular}{|c|c|c|c|}
\hline Group I (combat sports) & $\begin{array}{c}\text { Body fat } \\
\text { Pre-LSCR (\%) }\end{array}$ & $\begin{array}{c}\text { Body fat } \\
\text { During-LSCR (\%) }\end{array}$ & $\begin{array}{c}\text { Difference in body fat } \\
(\%)\end{array}$ \\
\hline Boxing & $11.77 \pm 2.49$ & $12.94 \pm 2.79$ & $1.15 \pm 1.20$ \\
\hline Judo & $11.75 \pm 1.80$ & $12.75 \pm 2.07$ & $1 \pm 0.27$ \\
\hline Karate & $12.30 \pm 1.38$ & $13.40 \pm 1.60$ & $1.1 \pm 0.22$ \\
\hline Taekwondo & $12.05 \pm 1.05$ & $13.10 \pm 0.97$ & $1.05 \pm 1.28$ \\
\hline Pencak Silat & $13.07 \pm 1.03$ & $14.60 \pm 0.83$ & $1.53 \pm 0.74$ \\
\hline \multicolumn{4}{|l|}{ Group II (aesthetic sports) } \\
\hline Aerobic & $9.90 \pm 1.12$ & $9.95 \pm 1.10^{\dagger \uparrow^{* * \#}}$ & $0.05 \pm 0.39$ \\
\hline Artistic gymnastics & $9.30 \pm 1.87$ & $9.46 \pm 1.89^{\dagger * * \#}$ & $0.16 \pm 0.40$ \\
\hline Synchronized diving & $9.47 \pm 0.83$ & $9.73 \pm 0.96^{\dagger * \#}$ & $0.27 \pm 0.46$ \\
\hline
\end{tabular}

Pre-LSCR - Pre-large-scale social restrictions in DKI Jakarta; During-LSCR - during the large-scale social restrictions in DKI Jakarta. $\dagger$ values significantly different compared with Boxing, $\ddagger$ values significantly different compared with Judo, ${ }^{\wedge}$ values significantly different compared with Karate, * values significantly different compared with Taekwondo, \# values significantly different compared with Pencak Silat. 
athletes $(p=0.003)$. Moreover, synchronized diving athletes were lighter than boxing athletes $(p=0.001)$, judo athletes $(p=0.001)$, karate athletes $(p=0.001)$, taekwondo athletes $(p=0.001)$, pencak silat athletes $(p=0.001)$. There were no significant main effect for times $(p=0.581)$ or group $\mathrm{x}$ time $(p=1.001)$.

\section{Body fat}

In line with body mass results, there is a significant main effect for group ( $p=0.001)$. Concretely, percentage body fat of aerobic athletes were smaller than judo athletes $(p=0.001)$, karate athletes $(p=0.001)$, pencak silat athletes $(p=0.001)$, taekwondo athletes $(p=0.001)$, boxing athletes $(p=0.001)$. Percentage body fat of Artistic gymnastics were smaller than judo athletes $(p=0.001)$, karate athletes $(p=0.001)$, pencak silat athletes $(p=0.001)$, taekwondo athletes $(p=0.001)$, boxing athletes $(p=0.001)$. Moreover, percentage body fat of synchronized diving athletes were smaller than judo athletes $(p=0.001)$, karate athletes $(p=0.001)$, pencak silat athletes $(p=0.001)$, taekwondo athletes $(p=0.001)$, boxing athletes $(p=0.001)$. ANOVA also shown significant main effect for timer $(p=0.001)$, but not significant for group $\mathrm{x}$ time $(p=0.128)$.

\section{LS questionnaire}

The results of the LS questionnaire showed that all respondents in combat sports $(100 \%)$ and aesthetic sports $(100 \%)$ groups felt that practicing During-LSCR was much worse than practicing Pre-LSCR. However, on the question about satisfaction towards performing independent training During-LSCR, $90 \%$ of the total of 50 aesthetic sports athletes, responded with "very satisfying" for independent training During-LSCR, and only $10 \%$ felt it was "very unsatisfying". Meanwhile, for the combat sports group, $84 \%$ of the total 100 athletes felt independent training During-LSCR was "very unsatisfying", and 16\% stated that it was "very satisfying".

\section{Discussion}

The aim of this study was to analyze and compare the effects of the COVID-19 quarantine on body mass between combat and aesthetic sports athletes. In line with our hypothesis, the findings of this study showed that combat sports athletes experienced a higher increase in body mass than aesthetic sports athletes. To be more specific, our hypothesis said that the characteristics of combat sports as contact sports might become a hindrance for practicing well during the pandemic, while aesthetic sports, as non-contact, would not experience such a problem. It was proven by the findings that aesthetic sports athletes had a higher number of "very satisfying" responses towards training DuringLSCR than combat sports athletes (90\% vs $16 \%)$.

To be more specific, we assumed that aesthetic sports athletes were more satisfied with independent training During-LSCR because they were still able to train well even with the physical distancing policy in effect. In other words, since aesthetic sports were noncontact, the athletes did not need any partners in practicing, hence the social distancing policy provided no difficulties. On the contrary, combat sports athletes were unsatisfied with independent training during pandemic because they had to start practicing in a new normal lifestyle in which they could not train with partners. We assumed that the "very unsatisfying" response stated by combat sports athletes regarding training During-LSCR was due to the fact that the athletes were required to train without a partner in accordance with the physical distancing policy during COVID-19 pandemic.

The correlation between social interaction and the quality of training was explored in a previous study [23]. Nia et al., [23] stated that there was a positive correlation between social interaction and the decrease of cortisol awakening responses (CAR) in aerobic training. In their conclusion, Nia et al. [23] explained that the CAR decrease was due to the decrease in stress levels and the increase of satisfaction with aerobic training. Even though that study was not conducted in a pandemic situation, its result was supported by the findings of this study, namely, that combat sports athletes did not have social interaction (partnership) during training and hence experienced a decrease in satisfaction level toward the training.

The results of the LS questionnaire were in line with the findings of the body mass increase in both groups. Combat sports athletes who were found to be unsatisfied with independent training During-LSCR experienced higher increase in body mass than aesthetic sports athletes. In other words, aesthetic sports athletes who had a good satisfaction level with training During-LSCR experienced lower body mass increase than combat sports athletes. These findings were congruent with a previous study which stated that the intensity and quality of training could affect the diet quality of an athlete [24]. To be more specific, Hyatt et al. [24] outlined that female volleyball players' body mass would always increase after the preseason long break. It was because the athletes did not do much quality training during the break.

The body mass increase in combat sports found in this study supported the previous study conducted by Hyatt et al. [24] Even though the two studies were conducted in different situations, the present study showed that the effects of independent training due to the COVID-19 pandemic could reduce the quality of exercise, leading to body mass increase in combat sports athletes. Meanwhile, this did not apply to aesthetic sports 
athletes, because even in an independent training situation in the midst of the COVID-19 pandemic, the quality of aesthetic sports training could still be maintained with good quality, thus causing no significant body mass increase compared to combat sports athletes.

The findings of this study, that combat sports athletes experienced body mass increase during the pandemic, support a previous study by Herrera-Valenzuela [21]. In Herrera-Valenzuela's study [21], it was concluded that Brazilian Jiu-Jitsu, boxing, Judo, Karate, Kickboxing \& Muay Thai, Mixed Martial Arts, and Taekwondo athletes had experienced body mass increase during the 20-day quarantine period in the COVID-19 pandemic. Although the findings of the present study were similar to previous studies, this study presents certain novel aspects such as (1) the inclusion of certain combat sports such as Pencak Silat, (2) the measurement of a longer quarantine period, (3) and the comparisons with aesthetics sports. These aspects further strengthen the point that combat sports athletes faces more risks of body mass increase during the pandemic.

The findings on body mass increase during the pandemic actually serve as a warning for combat sport trainers, athletes, sports scientists, or other health stakeholders to carefully consider any training designs given to combat sports athletes aiming towards reducing their body mass during the pandemic. This is very reasonable considering that before the pandemic there were problems related to rapid weight loss in combat sports, which could put the athletes at a health risk $[15,16,25]$. For example, a previous study showed that many combat sports athletes might experience a weight loss or body mass decrease by $2 \%$ to $10 \%$ during the week preceding the competition [15]. They do this in order to compete in lighter divisions and gain the advantage of getting smaller and weaker opponents.

In this context, the findings of the present study encouraged every federation of combat sports to pay careful consideration to and to reevaluate every regulation pertaining with division determination based on body mass or weight. The findings of this study showed that an increase in body mass was more than average during the pandemic, which would present greater difficulties for a combat sports athlete to reduce their weight for a match during the pandemic. For instance, an athlete who competed in the $66 \mathrm{Kg}$ division and weighted $70 \mathrm{Kg}$ in a normal period would have to lose at least $5 \mathrm{Kg}$ prior to the competition. However, during the pandemic, the average body mass increase was 2 to $3 \mathrm{Kg}$. This would force the athlete to work harder to reduce weight, and such rapid weight loss might negatively affect the athlete's health. It might even increase the risk of death.

Finally, this study proved that both combat sports and aesthetic sports groups experienced an increase in body mass. However, the combat sports group experienced a more significant increase in body mass than aesthetic sports group. This study encouraged sports nutritionists, coaches, and athletes to work on the nutrition (diet) and training design for the COVID-19 pandemic to maintain athletes' physical condition and body mass in order to reduce the negative risks of a high increase in body mass as well as the risks of mistakes in decreasing combat sports athletes' body mass. Regarding another point, this study was not free of limitations. Therefore, it was suggested that (1) further studies might implement more accurate psychological measurement parameters to measure the correlation between body mass increase and athletes' psychological condition during the pandemic, and that (2) this study only recruited 150 subjects (100 combat sports athletes, and 50 aesthetic sports athletes) which means the sample size of this study was not balanced. Further study required to analyze female athletes and more aesthetic sports athletes. However, it should be noted that those limitations did not diminish the benefits of the findings in this study, which could be used by sports nutritionists, coaches, and athletes to determine certain policies regarding nutrition and training design suitable for the COVID-19 pandemic.

\section{Conclusion}

This study shows that aesthetic sports lighter than combat sports during the 20-day quarantine period in the COVID-19 pandemic. The findings of this study should encourage sport nutritionists, coaches, and athletes to develop policies regarding nutrition and training design during the COVID-19 pandemic.

\section{Acknowledgment}

The authors are grateful to Indonesia's Committee of Sports (KONI) DKI Jakarta that has aided in the data collecting process.

\section{Funding}

This research received no external funding.

\section{Conflict of Interest}

The authors declare that there are no conflicts of interest.

\section{References}

1. Kakodkar P, Kaka N, Baig MN. A Comprehensive literature review on the clinical presentation, and management of the pandemic coronavirus disease 2019 (COVID-19). Cureus. 2020 Apr 6; 12(4): e7560. 
2. Baloch S, Baloch MA, Zheng T, Pei X. The Coronavirus disease 2019 (COVID-19) pandemic. Tohoku J Exp Med. 2020; 250(4): 271-8.

3. Lotfi M, Hamblin MR, Rezaei N. COVID-19: Transmission, prevention, and potential therapeutic opportunities. Clin Chim Acta. 2020; 508: 254-66.

4. Wilson MG, Hull JH, Rogers J, Pollock N, Dodd M, Haines J, Harris S, Loosemore M, Malhotra A, Pieles G, Shah A, Taylor L, Vyas A, Haddad FS, Sharma S. Cardiorespiratory considerations for return-to-play in elite athletes after COVID-19 infection: a practical guide for sport and exercise medicine physicians. Br J Sports Med. 2020; 54(19): 1157-61.

5. Carmody S, Murray A, Borodina M, Gouttebarge V, Massey A. When can professional sport recommence safely during the COVID-19 pandemic? Risk assessment and factors to consider. Br J Sports Med. 2020; 54(16): 946-8.

6. Reyes-Olavarría D, Latorre-Román PÁ, GuzmánGuzmán IP, Jerez-Mayorga D, Caamaño-Navarrete F, Delgado-Floody P. Positive and negative changes in food habits, physical activity patterns, and weight status during COVID-19 confinement: associated factors in the Chilean population. Int J Environ Res Public Health. 2020; 17(15): 5431.

7. Morin CM, Carrier J, Bastien C, Godbout R; Canadian sleep and circadian network. sleep and circadian rhythm in response to the COVID-19 pandemic. Can J Public Health. 2020; 111(5): 654-7.

8. Majumdar P, Biswas A, Sahu S. COVID-19 pandemic and lockdown: cause of sleep disruption, depression, somatic pain, and increased screen exposure of office workers and students of India. Chronobiol Int. 2020; 37(8): 1191-200.

9. Kass DA. COVID-19 and severe obesity: a big problem? Ann Intern Med. 2020; 173(10): 840-1.

10. Torales J, O’Higgins M, Castaldelli-Maia JM, Ventriglio A. The outbreak of COVID-19 coronavirus and its impact on global mental health. Int J Soc Psychiatry. 2020; 66(4): 317-20.

11. Dwyer MJ, Pasini M, De Dominicis S, Righi E. Physical activity: Benefits and challenges during the COVID-19 pandemic. Scand J Med Sci Sports. 2020; 30(7): 1291-4.

12. Ackland TR, Lohman TG, Sundgot-Borgen J, Maughan RJ, Meyer NL, Stewart AD, Müller W. Current status of body composition assessment in sport: review and position statement on behalf of the ad hoc research working group on body composition health and performance, under the auspices of the I.O.C. Medical Commission. Sports Med. 2012; 42(3): 227-49.
13. Artioli GG, Saunders B, Iglesias RT, Franchini E. It is time to ban rapid weight loss from combat sports. Sports Med. 2016; 46(11): 1579-84.

14. Brito CJ, Roas A FC, Brito I SS, Marins J CB, Córdova $\mathrm{C}$, Franchini E. Methods of body mass reduction by combat sport athletes. Int J Sport Nutr Exerc Metab. 2012; 22(2): 89-97.

15. Gann JJ, Tinsley GM, La Bounty PM. Weight Cycling: Prevalence, strategies, and effects on combat athletes. Strength Cond J. 2015; 37(5): 105-11.

16. Franchini E, Brito CJ, Artioli GG. Weight loss in combat sports: physiological, psychological and performance effects. J Int Soc Sports Nutr. 2012; 9(1): 52.

17. Mathisen TF, Heia J, Raustøl M, Sandeggen M, Fjellestad I, Sundgot-Borgen J. Physical health and symptoms of relative energy deficiency in female fitness athletes. Scand J Med Sci Sports. 2020; 30(1): 135-47.

18. Sterkowicz-Przybycien K, Gualdi-Russo E. Evaluation of somatotype in artistic gymnastics competitors: a meta-analytical approach. J Sports Med Phys Fit. 2019; 59(3): 449-55.

19. Mkaouer B, Hammoudi-Nassib S, Amara S, Chaabène $\mathrm{H}$. Evaluating the physical and basic gymnastics skills assessment for talent identification in men's artistic gymnastics proposed by the International Gymnastics Federation. Biol Sport. 2018; 35(4): 383-92.

20. Yeo TJ. Sport and exercise during and beyond the COVID-19 pandemic. Eur J Prev Cardiol. 2020; 27(12): 1239-41.

21. Herrera-Valenzuela T, Narrea Vargas JJ, Merlo R, Valdés-Badilla PA, Pardo-Tamayo C, Franchini E. Effect of the COVID-19 quarantine on body mass among combat sports athletes. Nutr Hosp. 2020 Dec 16;37(6):1186-1189.

22. Ammar A, Brach M, Trabelsi K, Chtourou H, Boukhris O, Masmoudi L, et al. Effects of COVID-19 Home Confinement on Eating Behaviour and Physical Activity: Results of the ECLB-COVID19 International Online Survey. Nutrients. 2020; 12(6): 1583.

23. Ramania N, Apriantono T, Winata B. The effects of differences in sleep quality and quantity on VO2max levels. Adv Rehab. 2020; 34(4): 11-7.

24. Hyatt HW, Kavazis AN. Body Composition and perceived stress through a calendar year in NCAA I female volleyball players. Int J Exerc Sci. 2019; 12(5): 433-43.

25. Horswill CA, Scott JR, Dick RW, Hayes J. Influence of rapid weight gain after the weigh-in on success in collegiate wrestlers. Med Sci Sports Exerc. 1994; 26(10): 1290-4. 